\title{
Improved Wells Turbine using a Concave Sectional Profile
}

\author{
Reza Valizadeh ${ }^{*}$, Madjid Abbaspour ${ }^{1}$, Mohammad Taeibi Rahni1 ${ }^{1,2}$, Mohsen Saffari Pour ${ }^{3,4}$, Christopher \\ Hulme-Smith ${ }^{4^{*}}$ \\ 1. Department of Mechanical Engineering, Sharif University of Technology, Tehran, Iran; abbpor@sharif.edu \\ 2. Aerospace Research Institute, Ministry of Science and Technology; taeibi@ari.ac.ir \\ 3. Department of Mechanical Engineering, Shahid Bahonar University of Kerman, Kerman, Iran; mohsensp@kth.se \\ 4. Department of Materials Science and Engineering, KTH Royal Institute of Technology, Stockholm, Sweden \\ * Correspondence: rezavalizaadeh@gmail.com; chrihs@kth.se
}

\begin{abstract}
The current need to develop sustainable power sources has led to the development of ocean-based conversion systems. Wells turbine is a widely used converter in such systems which suffers from a lack of operational range and power production capacity under operational conditions. The profile named IFS which is concave in the post-mid-chord region, can produce significantly larger lift forces and show better separation behavior than the NACA profiles. In the present study, we tested this profile for the first time in a Wells turbine. The performance of six different blade designs with IFS and NACA profiles were evaluated and compared using a validated computational fluid dynamic model. Although the substitution of the NACA profile with the IFS profile in all cases increased the torque generated, the most efficient power generation and the largest efficient range were achieved in the design with varying thickness from the hub with a 0.15 thickness ratio reaching to the ratio of 0.2 at the tip. The operational span of this design with the IFS profile was $24.1 \%$ greater and the maximum torque generation was $71 \%$ higher than the case with the NACA profile. Therefore, the use of the IFS profile is suggested for further study and practical trials.
\end{abstract}

Keywords: Wells turbine, oscillating water column, wave energy converter, computational fluid dynamics

\section{Nomenclature}

Abbreviations

BL

Boundary layer

BSB20

Backward Swept Blade with Thickness ratio of $20 \%$

BSB20IFS

BSB20 with the IFS profile

BSB20NACA

BSB20 with the IFS profile

СТВ20

Constant Thickness Blade with Thickness ratio of $20 \%$

CTB25

Constant Thickness Blade with Thickness ratio of $25 \%$

CTB20IFS

CTB20 with the IFS profile

CTB25IFS

CTB25 with the IFS profile

CTB20NACA

CTB20 with the IFS profile

CTB25NACA

CTB25 with the IFS profile 


\begin{tabular}{|c|c|}
\hline CFD & Computational fluid dynamics \\
\hline FSB20 & Forward Swept Blade with Thickness ratio of $20 \%$ \\
\hline FSB20IFS & FSB20 with the IFS profile \\
\hline FSB20NACA & FSB20 with the IFS profile \\
\hline HV & Horseshoe Vortices \\
\hline MTC & Maximum Torque Coefficient \\
\hline ME & Maximum efficiency \\
\hline NS & Navier Stokes Equation $\mathrm{s}$ \\
\hline OWC & Oscillating Water Column \\
\hline PS & Pressure side \\
\hline $\mathbf{R} 30 \%$ & Range of operational span with efficiency more than $30 \%$ \\
\hline RANS & Reynolds Averaged Navier Stokes \\
\hline SS & Suction side \\
\hline TLV & Tip Leakage Vortices \\
\hline VTB20 & Varying Blade Thickness with Thickness ratio of $20 \%$ at the tip \\
\hline VTB25 & Varying Blade Thickness with Thickness ratio of $25 \%$ at the tip \\
\hline VTB20IFS & VTB20 with the IFS profile \\
\hline VTB25IFS & VTB25 with the IFS profile \\
\hline VTB20NACA & VTB20 with the IFS profile \\
\hline VTB25NACA & VTB25 with the IFS profile \\
\hline \multicolumn{2}{|l|}{ Symbols } \\
\hline $\begin{array}{l}\text { ro } \\
\text { bl }\end{array}$ & rotational velocity along the \\
\hline unifo & uniform air velocity \\
\hline press & \\
\hline $\mathrm{rad}$ & \\
\hline
\end{tabular}




\begin{tabular}{|c|c|}
\hline$\omega$ & angular Velocity \\
\hline$\alpha$ & angle of Attack \\
\hline $\boldsymbol{W}$ & relative velocity \\
\hline$F_{A}$ & axial Force \\
\hline$F_{T}$ & tangential Force \\
\hline $\mathbf{t}$ & Thickness Ratio \\
\hline$R_{t}$ & tip radius \\
\hline$r_{t}$ & tip radius \\
\hline$r_{h}$ & hub radius \\
\hline $\boldsymbol{b}$ & Span \\
\hline$c$ & Chord \\
\hline$\phi$ & flow coefficient \\
\hline$L$ & lift force \\
\hline$D$ & drag force \\
\hline$T$ & Torque \\
\hline$f$ & Frequency \\
\hline$C_{c P}$ & center of pressure \\
\hline$c_{\operatorname{lmax}}$ & 2D maximum lift coefficient \\
\hline $\boldsymbol{R e}$ & Reynolds number \\
\hline$\rho$ & Density \\
\hline$\Delta \boldsymbol{P}_{0}$ & static pressure drop \\
\hline
\end{tabular}




\author{
$Q \quad$ volumetric flow rate \\ $\eta \quad$ Efficiency \\ Superscripts \\ $(-)^{\prime} \quad$ fluctuating component \\ $\overline{(-)} \quad$ mean component \\ $(-)^{*} \quad$ non-dimensionalized parameter
}

\title{
1. Introduction
}

The world's need for energy is increasing and the devastating effects of fossil fuel consumption has made humankind to seek every extractable and sustainable form of energy. One such source of energy is the sea. The power density of ocean-based generation is higher than wind and solar-based techniques. Furthermore, many populated societies live close to coastlines, which reduces the need for electricity distribution infrastructure from costal sources. Many of the countries with large coastal areas such as the UK, India, Australia, and the USA are the leading countries in developing ocean-based power systems [1, 2]. One of the most significant sources of energy from the ocean is from waves as they reach the shore. In 2000, the incident waves of the Pacific Ocean produced nearly as much energy as the entire world's electrical power consumption [3]. The kinetic energy of the waves must be converted into electricity. One candidate conversion system is the oscillating water column (OWC) which is demonstrated in Fig. 1. This system is amongst the most developed techniques and is already deployed. However, the most important component of the system is a self-rectifying air turbine, which is not yet effective in real sea conditions since such turbines have inferior operational range and power production than other candidate systems [4-6]. The OWC consists of a capture chamber that contains a fixed amount of air which is connected to a duct containing the turbine as shown in Fig. 1. Fluctuation of the water surface changes the pressure level in the chamber and consequently induces reversible bi-directional flow which acts as the working fluid for the self-rectifying turbine [7- 11]. 


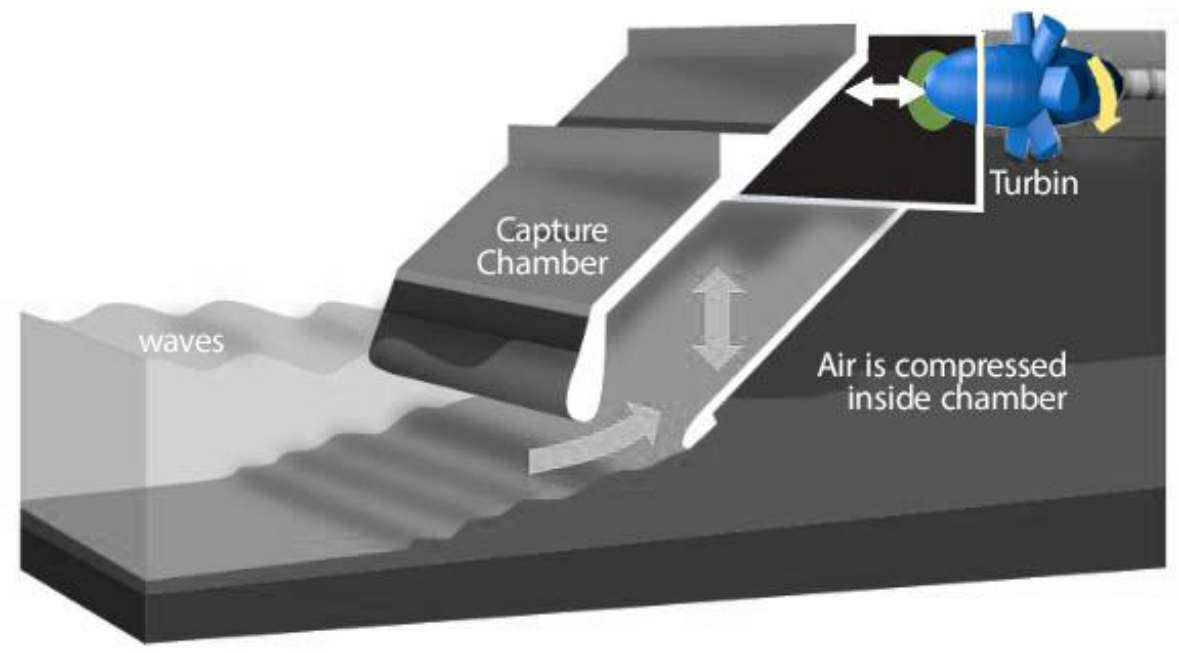

Fig. 1. A schematic demonstration of an OWC system matched a Wells turbine.

The Wells turbine is a practical and inexpensive axial self-rectifying turbine. It is often used for low flow velocities such as those produced by oceanic incident waves [13-15]. The Wells turbine rotor as shown in Fig. 2 has several blades with symmetrical profiles as their sectional profile which are radially installed around the hub and with a stagger angle of $90^{\circ}$. Considering an air profile in a free stream with the relative velocity, $w$, and relative angle of attack to the chord, $\alpha$, the lift and drag forces are produced on the airfoil. For a Wells turbine blade with an airfoil section, the incident flow attacks with the absolute velocity $V_{\infty}$ on a cascade with the angular velocity of $U=r \omega$. The resulting velocity is a relative velocity with an angle of attack $\alpha=\tan ^{-1}\left(V_{\infty} / U\right)$. The tangent of this angle of attack is the non-dimensional flow coefficient as defined in Eq. 1. The angles of attack and relative velocities over sectional profile result in lift and drag forces which can be resolved into tangential (Eq. 2) and axial (Eq. 3) forces on the blade as shown in Fig. 3. The blade section of a Wells turbine is symmetrical and so the tangential force generates torque always in the same direction regardless of the direction of air flow. The Wells turbine produces a positive time-averaged power due to the low frequencies of wave motion [16-19].

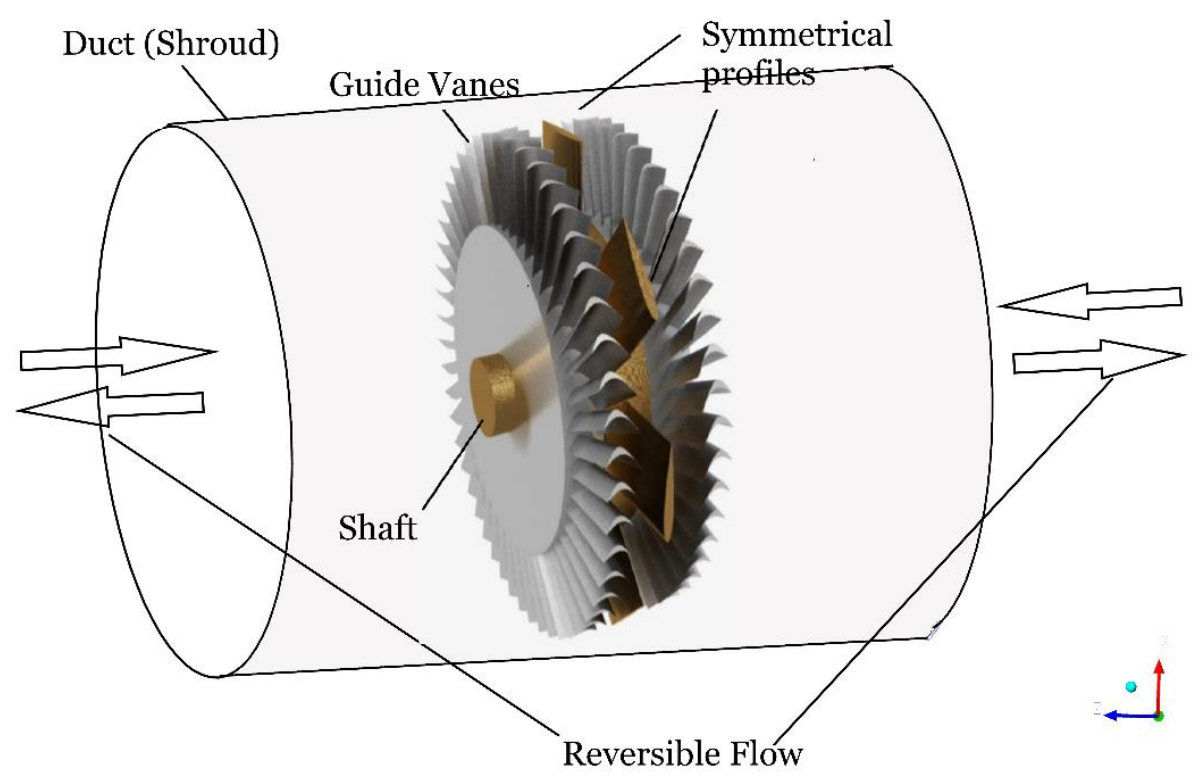


Fig. 2. A schematic of a Wells turbine's rotor.

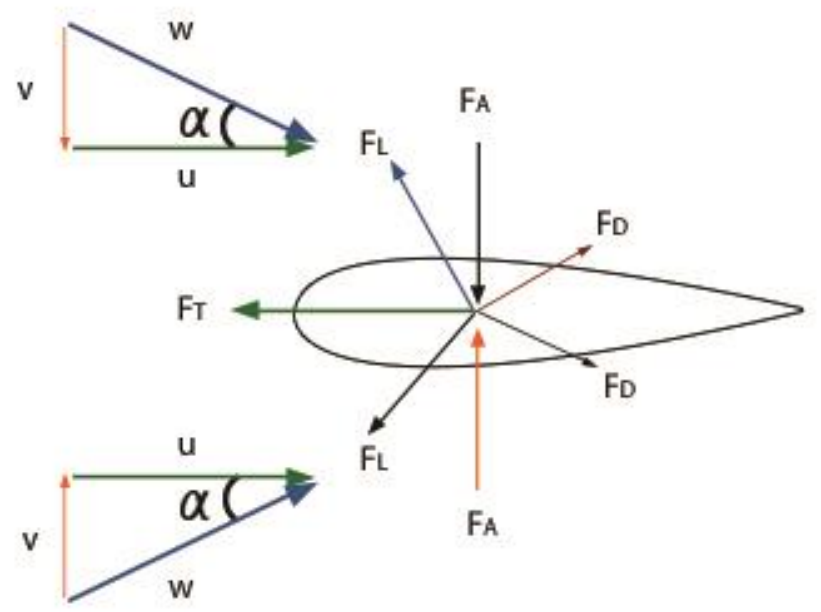

Fig. 3. The resolved forces on the Wells turbine blade's section and the geometrical variables of the blade.

$$
\begin{aligned}
& \phi=\tan \alpha=V / R_{\text {tip }} \omega \\
& F_{A}=L \cos \alpha+D \sin \alpha \\
& F_{T}=L \sin \alpha-D \cos \alpha
\end{aligned}
$$

Wells turbines suffer from narrow operational range due to suction side stalling and a low tangential component of the lift force, which leads to low torque and, therefore, low power generation $[8,20]$. Waves change randomly in power and frequency and so the reversing flow may experience sudden changes which stall the turbine. Employing the profiles with greater stall angle and high lift generation is an effective solution to resolve this issue. Many attempts have been made to improve performance through geometrical modification. In the current study, the blade profile is considered. The effects of sectional profile thickness of the blade on the performance of both starting and running regimes have been investigated experimentally [18]. Thicker profiles enabled the turbine to have better efficiency and wider efficient range because of the onset of stalling was more gradual. In a fixed pressure drop state, the increase of thickness led to the increase of torque generation and better starting behavior [16, 21-23]. The performance of a small-scale Wells turbine with four different profiles and two sweep ratios of 0.5 and 0.35 has also been investigated [24]. A sweep ratio of 0.35 and the thickness ratio of $20 \%$ were found to be optimum. Studies into the effect of sweep ratio on the operational range of the Wells turbine have shown that a sweep ratio of 0.35 is most efficient [24- 26]. As far as the scale is concerned, studies of the profile thickness showed that $20 \%$ thickness is favorable for smaller scales while $15 \%$ is better for large scales [26-28]. A mathematical multi-objective optimization algorithm coupled with computational fluid dynamics (CFD) was used to investigate swept designs [29,30]. The torque coefficient and the stall margin were increased substantially for forward-swept turbines. A study of blades with constant thickness and variable thickness was investigated using CFD and experiments, showing that variable thickness has greater performance [31]. Variable thickness blades also generate less entropy [20]. Another study used two-dimensional CFD to optimize the geometry called "NACA 0021" for application in the Wells turbine and was able to increase the tangential force by $8.8 \%$ and an insignificant increase of $0.2 \%$ in the efficiency [32]. An improved profile with a $5 \%$ better efficiency was obtained from an initial 
airfoil design from the wind turbine industry named "S809M" using a similar CFD procedure [32, 33]. Using the "S1046" profile in the Wells turbine improved torque generation by $3 \%$ in a water environment compared to the "NACA 0015" profile [34]. A numerical optimization of the NACA0015 profile produced a new profile with a surface that was almost linear after the mid-chord point and a slightly concave profile near the trailing edge. This design generated $14 \%$ more torque in three-dimensional simulations [35]. Mathematical optimization algorithms have allowed such geometries to be discovered but such methods require a large number of simulation cases to achieve reasonable results. This significantly increases the project time and costs. Most modified geometries mentioned in this review have not yet been validated experimentally.

In addition to the modifications reviewed above, there is a turbine profile from the marine sector that yet has not been considered for use in Wells turbines, even though it is known that it generates more lift than the NACA series: IFS (Institute Fur Schiffbau). IFS profiles were designed experimentally [36, 39]. They have a very high lift to drag ratio, optimized for best functionality in rudders. The IFS profile series have a steep lift curve before the stall and capability to postpone the separation bubbles formation [36, 37]. The higher lift generation of the IFS profile enables the turbine to work over a broader range of flow coefficients. This is advantageous for OWC applications in variable sea conditions. It is also useful to compare aerodynamic properties of the IFS and NACA profiles. Table 1 and Fig. 4 help us to better characterize the two profiles performance based on aerodynamic parameters which are the well-known Reynolds number, CL as the Lift coefficient and is the $\alpha_{\mathrm{s}}$ angle of attack at the onset of a stall. Evidently from Table 1 we see that in contrast with the NACA series, the lift production of the IFS series increases substantially with thickness. This feature is beneficial in the Wells turbine application since the thicker profiles are better in terms of working range and torque generation [29]. The thicker versions of IFS profile produce more lift and hence more tangential force than thick NACA profiles. Therefore, such profiles can be an effective solution for the main gap of the Wells turbine which is narrow operational range and weak power generation. The current study, we aimed to test and analyze using of IFS profile in the application of the Wells turbine for the first time via a three-dimensional CFD setup.

Table 1. Aerodynamic properties of IFS and NACA profiles. These data are collected from the CFD studies accompanied by the three-dimensional wind tunnel tests. [38-40]

\begin{tabular}{|c|c|c|r|r|c|}
\hline Reference & Method & Profile & $\begin{array}{c}\text { Re } \\
\text { (million) }\end{array}$ & Cl max & $\alpha_{S}$ \\
\hline $\begin{array}{c}\text { Thieme } \\
1962[39]\end{array}$ & Wind Tunnel 3d & NACA 0025 & 0.78 & 1.34 & 46 \\
\hline$“$ & Wind Tunnel 3d & IFS 62TR 25 & 50 & 1.47 & 44 \\
\hline $\begin{array}{c}\text { El Moctar } \\
1998[40]\end{array}$ & RANS 2d & NACA 0025 & 50 & 1.88 & 18 \\
\hline$"$ & RANS 2d & IFS 62TR 25 & 50 & 2.11 & 21 \\
\hline$"$ & RANS 2d & NACA 0015 & 50 & 1.02 & N/A \\
\hline$"$ & RANS 2d & IFS 62TR 15 & 50 & 1.18 & N/A \\
\hline El Moctar & RANS 3d & NACA 0025 & 50 & 1.74 & 33 \\
\hline $1998[40]$ & & & & & \\
\hline$"$ & RANS 3d & IFS 62TR 25 & 50 & 2.05 & 31 \\
\hline
\end{tabular}




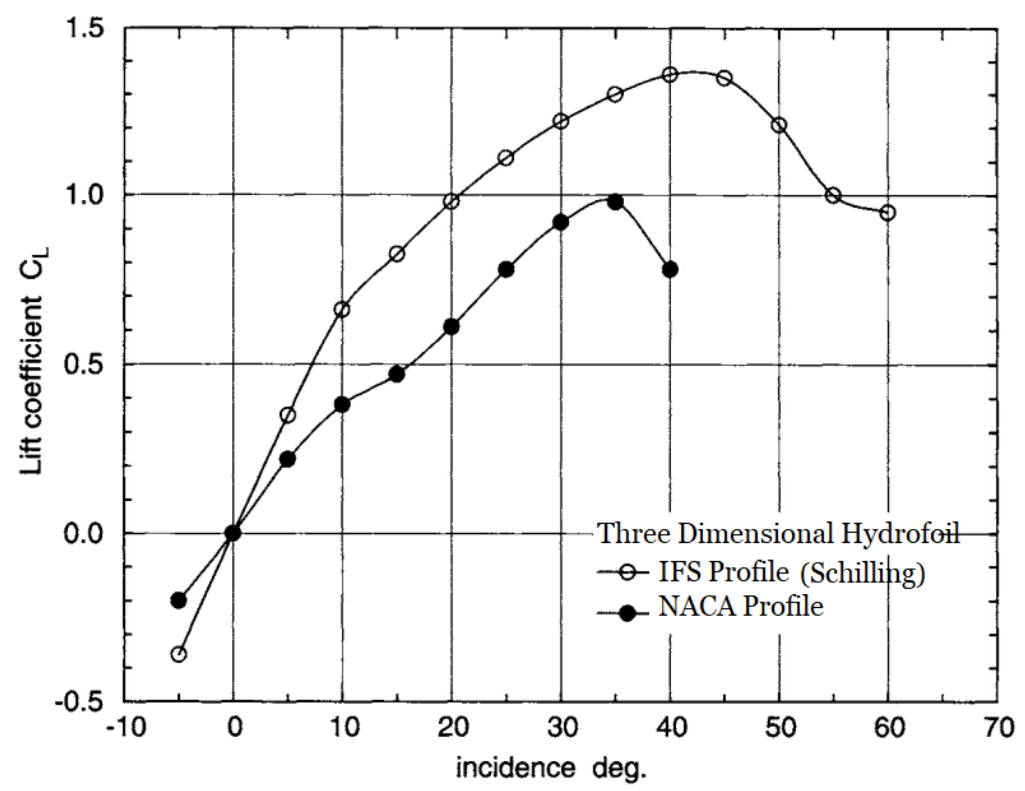

Figure 4. The lift coefficient trend of the IFS and NACA profile compared for a three dimensional hydrofoil against incidence angle.

Defining the profile curve with an approximate polynomial function based on Eq. 4, where $t$ is the thicknessto-chord ratio leads us to fixed coefficients for NACA and IFS series as brought in Table 2. Shape of the IFS profile is shown in Fig. 5 a for a thickness ratio of $20 \%$. four blade designs were generated with variable (VTBt) and constant $(\mathrm{CTBt})$ thickness ratios where $t$ is the thickness ratio. Two other designs are the backwards-swept and (BSBt) and forwards-swept blade (FSBt) with sweep ratio of 35\%. These designs are illustrated in Fig. 5b.

$$
y=t\left(a x^{6}+b x^{5}+c x^{4}+d x^{3}+e x^{2}+f x+g\right)
$$

Table 2. Fitted polynomial constants of IFS and NACA profiles.

\begin{tabular}{|l|l|l|l|l|l|l|l|}
\hline Profile & $\mathrm{a}$ & $\mathrm{b}$ & $\mathrm{c}$ & $\mathrm{d}$ & $\mathrm{e}$ & $\mathrm{f}$ & $\mathrm{g}$ \\
\hline NACA & $-1 \times 10^{-3}$ & $4.6 \times 10^{-3}$ & -0.72 & 0.60 & 2.6 & 6.0 & 0.68 \\
\hline IFS & $-1.4 \times 10^{-4}$ & $\mathbf{6 . 0} \times \mathbf{1 0}^{-2}$ & $-9.7 \times 10^{-2}$ & 0.80 & -3.6 & 7.5 & 0.59 \\
\hline
\end{tabular}

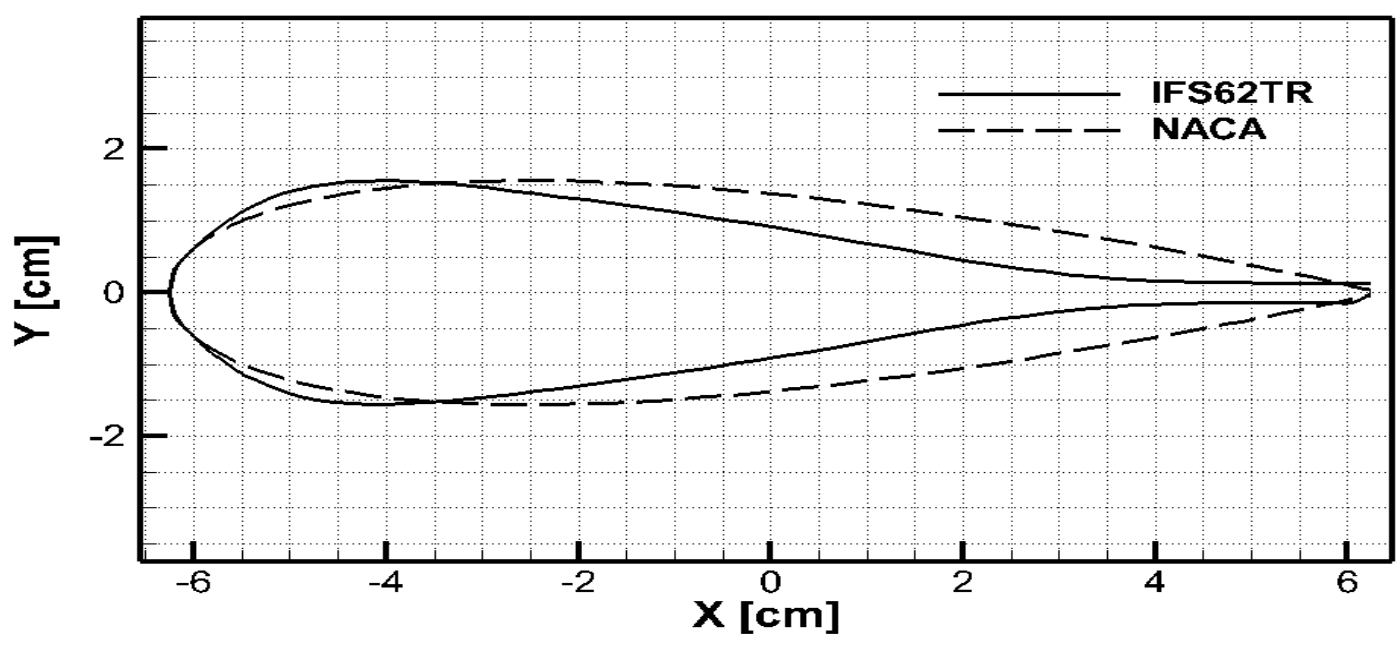

Fig. 5a. The geometry of NACA and IFS 62TR profiles. 


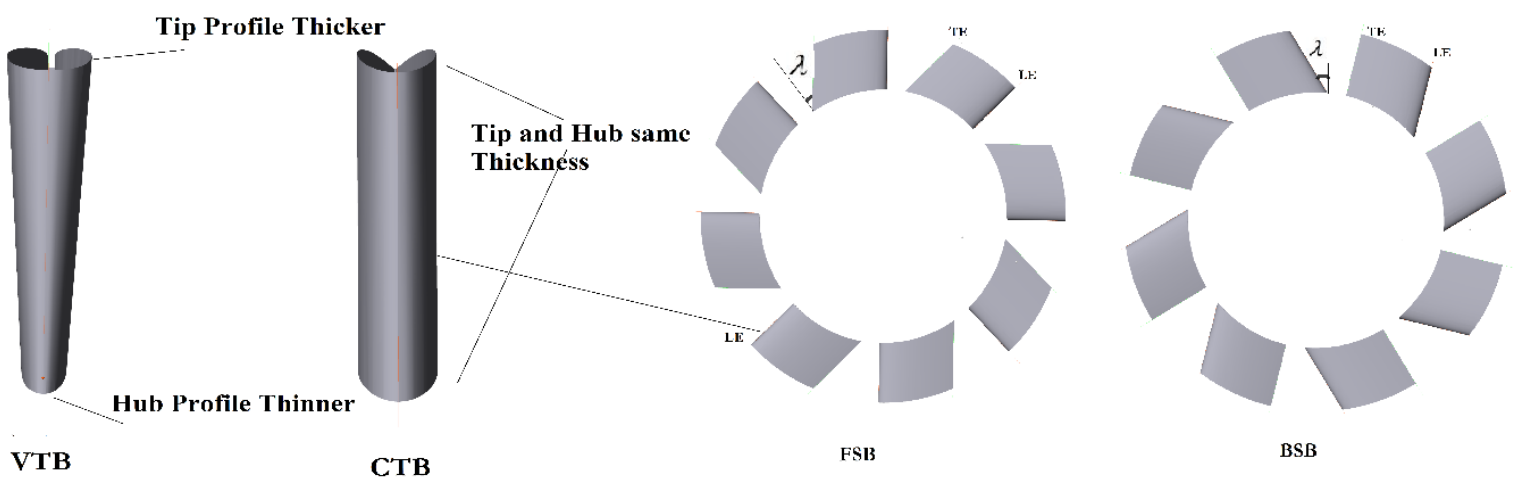

Fig. 5b. The two VTB and CTB blade designs viewed from the LE side, The BSB and FSB blade designs viewed from the inflow direction

\section{Materials and Methods}

The frequency, $f$, of the reversible air flows inside a wave energy system is minimal $(<0.1 \mathrm{~Hz})$, and so it is common to assume a quasi-steady-state flow for the simulation. This has been validated for simulations of Wells turbine $[2,9-11,16,20,21,41-45]$. This approach greatly reduces the computational expense of simulations and simplifies post-processing. In the quasi-steady-state approach, the turbine is tested only in one direction of the flow field since the dynamic effects of the low frequency flow on the performance of the turbine is negligible [2, 9-11, 16, 20, 21, 41-45]. In the current study, validation of the CFD set up was made based on the results of a previous study, for which the blade geometry is presented in Table 3 [13].

Table 3. Geometrical variables of the benchmark and the simulated case

\begin{tabular}{|c|c|}
\hline Blade profiles & $\begin{array}{c}\text { NACA } \\
0015\end{array}$ \\
\hline $\begin{array}{l}\text { Number of } \\
\text { blades }\end{array}$ & 8 \\
\hline $\begin{array}{l}\text { Blade chord } \\
\text { length }\end{array}$ & $0.125 \mathrm{~m}$ \\
\hline Hub diameter & $0.4 \mathrm{~m}$ \\
\hline Tip diameter & $0.59 \mathrm{~m}$ \\
\hline Tip clearance & $0.001 \mathrm{~m}$ \\
\hline
\end{tabular}

In the current case, the length downstream of the blade is more important than the length to the inlet because the numerical results are mostly affected by suction side phenomena. The outlet was placed far enough from the blade to ensure that the far-field wakes are attenuated. In this study, the sizing of the simulation domain is set to be 5 times the chord length upstream and 10 chords downstream (Fig. 6), respectively whereas in various studies, the sizing of the domain is less than our domain $[2,16,20,29-35,42-45]$. 


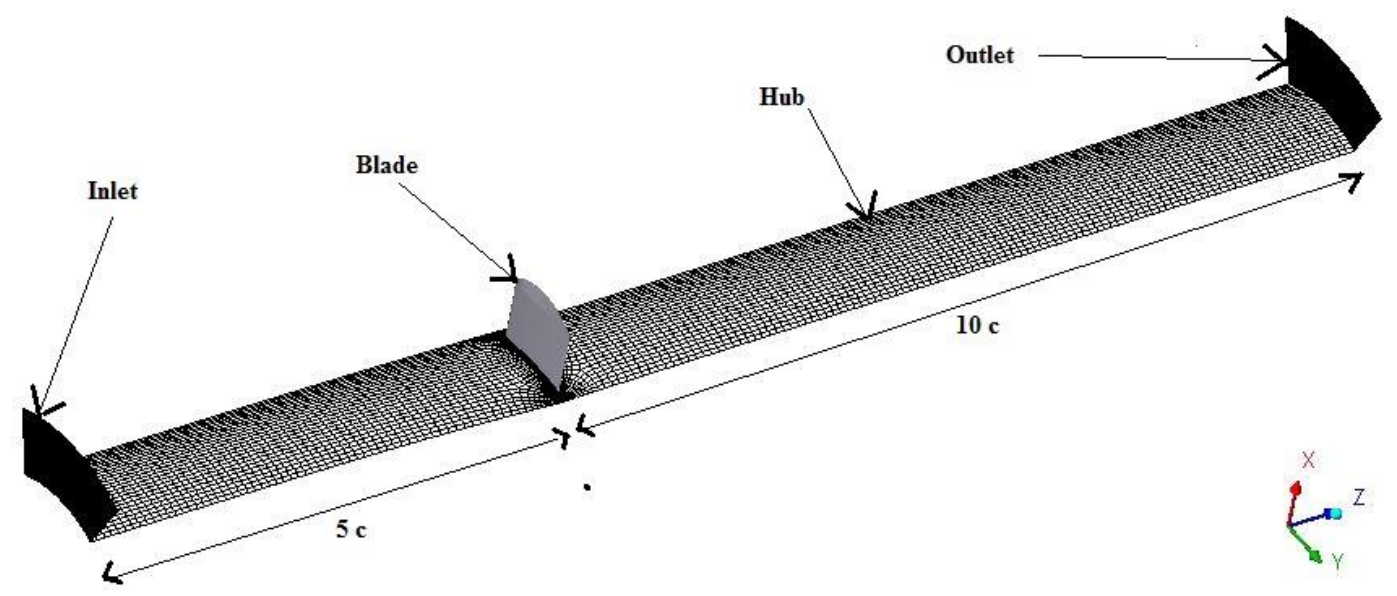

Fig. 6. The simulated domain for the present work, where $c$ is the chord length of the blade.

The efficiency of the turbine was calculated for five different numbers of grid cells in the flow coefficient, 0.10 . The variation in efficiency stops above 1.8 million cells (Fig. 7). Therefore, this number of cells was selected for the rest of the calculations.

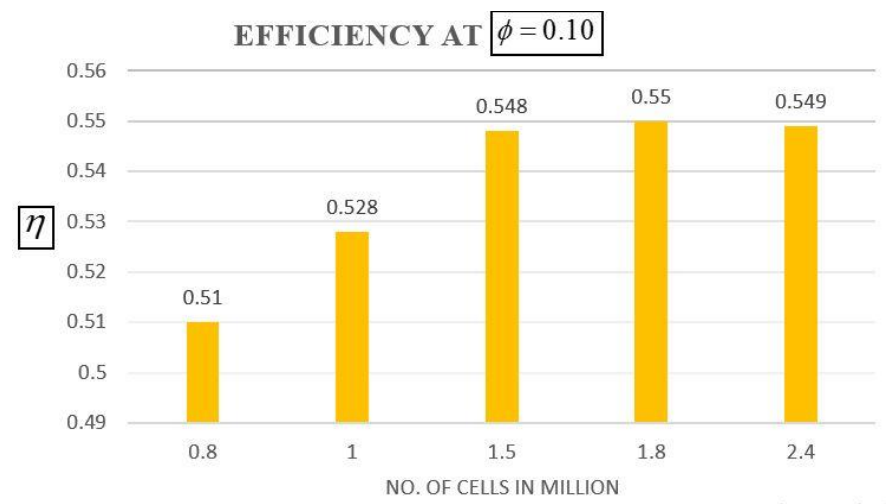

Fig. 7. Grid dependency of the setup with efficiency results in the flow coefficient, 0.10 .

The use of commercial softwares is common for simulation of turbomachinery systems such as the Wells turbine. ANSYS software was used in previous works for the three-dimensional simulation of the Wells turbine. Studies show that turbulence modelling based on the RANS Equations provides reliable results however choosing the right turbulence model is crucial to get a more accurate prediction of the turbine's performance specially near stall regime. Different solvers and turbulence models were used before and among them the $K-\omega$ SST model is more common. Table 4 summarizes the information of the simulation techniques employed by recent studies.

Table 4. CFD techniques used for simulation of the Wells turbine in previous studies.

\begin{tabular}{|l|l|l|l|}
\hline Numerical setup by & Solver & Turbulence model & Type of the mesh \\
\hline Das and Samad 2020 & CFX 16.1 & $K-\omega$ SST & Unstructured \\
\hline Valizadeh et al. 2020 & CFX 18 & $K-\omega$ SST & Structured \\
\hline Kumar et al. 2019 & CFX 15 & $K-\omega$ SST & Unstructured \\
\hline Kumar et al. 2019 & CFX 15 & $K-\omega$ SST & Unstructured \\
\hline Halder et al. 2018 & CFX 14.5 & $K-\omega$ SST & Structured \\
\hline Hashem et al. 2018 & Fluent & $K-\varepsilon$ realizable & Unstructured \\
\hline
\end{tabular}




\begin{tabular}{|l|l|l|l|}
\hline Shabaan 2017 & Fluent & $K-\varepsilon$ realizable & Structured \\
\hline Nazeryan et al. 2017 & CFX 17 & $K-\omega$ SST & Structured \\
\hline Ying Cui et al. 2016 & Fluent & $K-\varepsilon$ realizable & Structured \\
\hline Shabaan 2016 & Fluent & $K-\varepsilon$ & Structured \\
\hline Halder et al. 2016 & CFX 14.5 & $K-\omega$ SST & Unstructured \\
\hline Rasool 2015 & CFX 17 & $K-\varepsilon$ RNG & Structured \\
\hline Shabaan 2012 & Fluent & $K-\varepsilon$ realizable & Structured \\
\hline Torresi et al. 2007 & Fluent & $K-\omega$ SST & Structured \\
\hline
\end{tabular}

Turbulence modelling based on the RANS Equations cannot predict complex flow behaviour in the stall state of the Wells turbine accurately. This problem can be noticed in the studies presented in Table 4 and is intensified in one study, in which the torque amounts after the stall point rose, contradicting experimental observations [42]. $K-\omega$ SST is the best choice of turbulence model since it is more powerful than $K-\varepsilon$ model in predicting the onset and number of flow separation events with adverse pressure gradient such as the suction side of the Wells turbine [41-47]. In the proposed methodology we used this model. The domain was meshed using a structured high-quality hybrid O-H type of grid which is shown in Fig. 8. O-H type means there is a circular region around the sectional profile in which the density of mesh is greater and smartly increases near the blade. The far from blade the domain is divided by half $\mathrm{H}$ type regions to generate a structured mesh from inlet to $\mathrm{O}$ region and from $\mathrm{O}$ region to outlet. This mesh type is optimized for the meshing around the turbomachine blades with boundary layer consideration. This type allows to reach a very fine mesh around walls for better boundary layer simulation but not so dense mesh far from the walls to keep the total number of cells optimized. The concentration of the mesh around the walls is generated with the size of $5 \mu \mathrm{m}$ for the first cells to guarantee the $Y^{+}$around one which is the optimum condition for $K-\omega$ SST turbulence modelling.

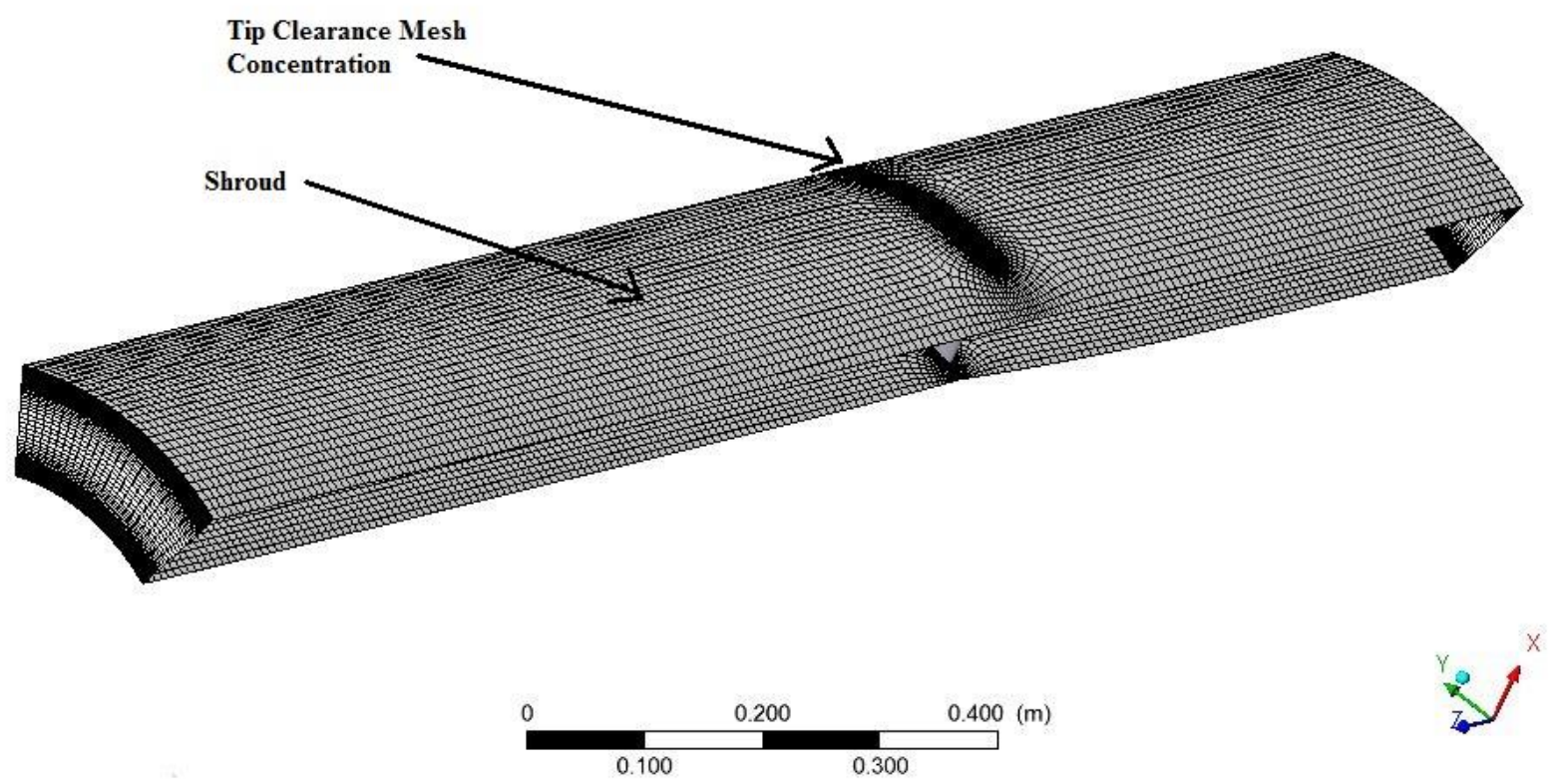

Fig. 8a. The domain and its three-dimensional mesh showing a very fine mesh around shroud and hub walls. 


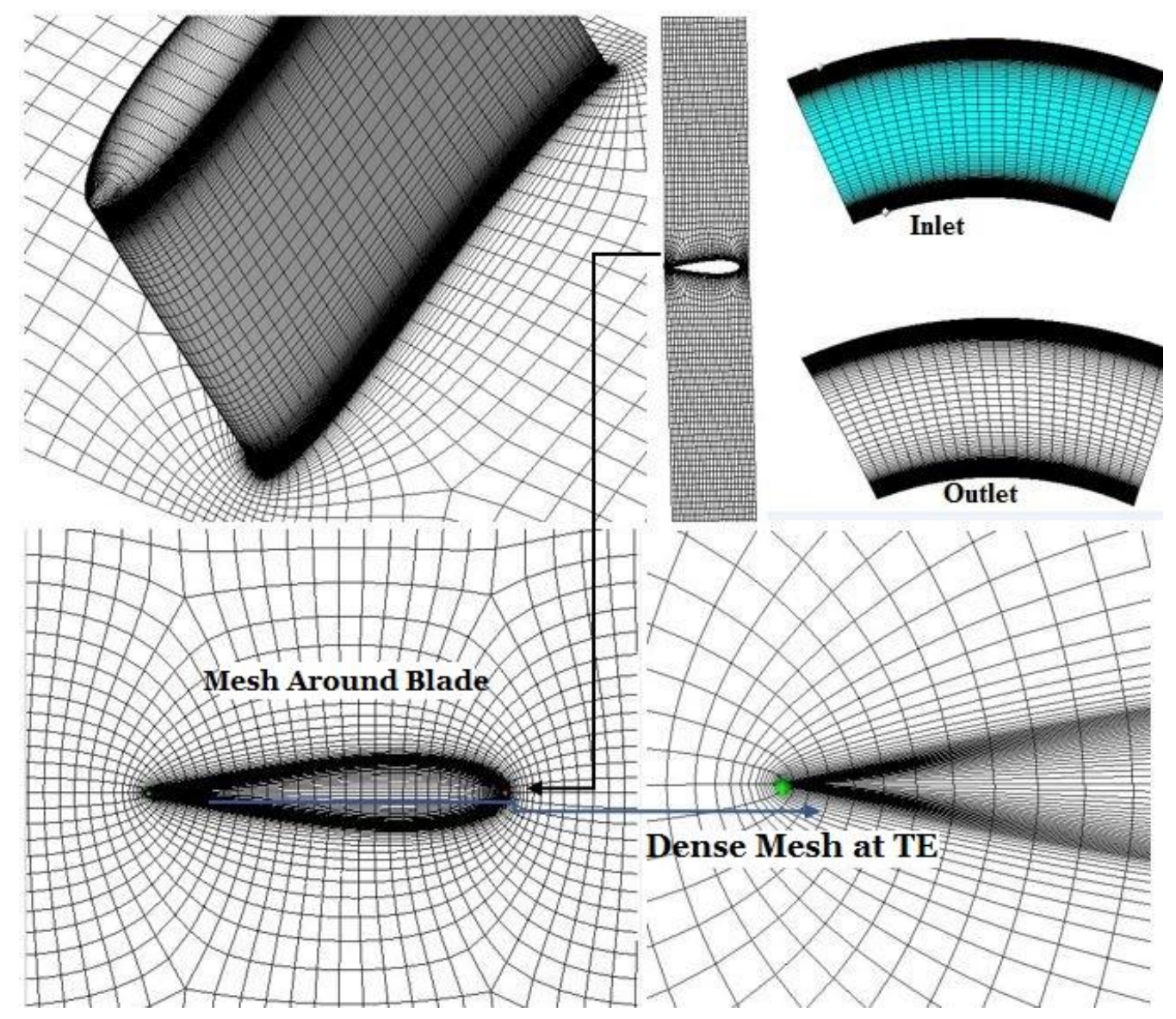

Fig. 8b. The high quality mesh around the blade showing a very fine mesh around leading edge (LE) and trailing edge (TE).

The Wells turbine's rotor has symmetry around the rotational axis. Hence, a moving reference frame can be used to avoid the high computational cost of simulating the whole rotor. This technique leads to the solution of the flow field around one blade by rotating the reference flow domain instead of the blade with the same rotational velocity as the rotor. This methodology is common in turbomachinery studies and provides accurate results while reduces the complexity of all CFD stages $[2,10,20,29,30,41-45]$. The angular velocity of the rotor was fixed to be $2000 R P M$ for all the simulations and it was equal to the velocity set in previous experiments [13]. Air at $25^{\circ} \mathrm{C}$ was selected as the fluid, and the reference pressure was set $1 \mathrm{~atm}$. The selected turbulence model was $K-\omega$ SST solved along with the Reynolds Averaged Navier-Stokes Equations using the finite volume discretization method and high-order upwind schemes for all the flow components. The turbulence intensity was set to be $10 \%$. Normal fixed velocity speed was set at the inlet, average static pressure was used for the outlet with a relative pressure of $0 \mathrm{~atm}$. Periodic boundaries were defined along the meridional surfaces. All other boundaries were defined to be walls with a no slip condition, including the blade, shroud and the hub.

\subsection{Validation of the setup}

The Wells turbine performance is evaluated with three main variables: torque coefficient, pressure drop coefficient and efficiency which are defined by Eq. $s 5$ to 7 respectively. The curve line for these three parameters is sketched in Figs. 9a, b, and c based on the flow coefficient variable which is the non-dimensional blade's velocity as shown in Eq. 1. This variable is introduced as the tangent of angle of incidence for the relative velocity at the tip's section in some literatures. The performance variables graphed in Fig. 9 show the satisfactory agreement with 
the experimental data [13]. The reason is the simulation data regarding the operational zone where the turbine is working in no stall region is predicted with even less relative error than CFD results of the benchmark [2]. The current results illustrate the right physical behavior of the flow around the Wells turbine's blade. However, in the stall and post-stall regions, the results are not accurate with respect to the experimental results. The reason is that, as discussed, the classic turbulence models based on RANS equations fail to accurately simulate the highly turbulent flow formed in the wake of the Wells turbine rotor. Nevertheless, the aim of this study was to provide reliable data for the flow coefficients before the stall regime where the use of the turbine is practical, and this goal is achieved by the present setup.

$$
\begin{aligned}
& T^{*}=\frac{T}{\rho \omega^{2} R_{t i p}{ }^{5}} \\
& \Delta P_{0}^{*}=\frac{\Delta P_{0}}{\rho \omega^{2} R_{t i p}{ }^{2}} \\
& \eta=\frac{T \omega}{Q \Delta P_{0}}
\end{aligned}
$$
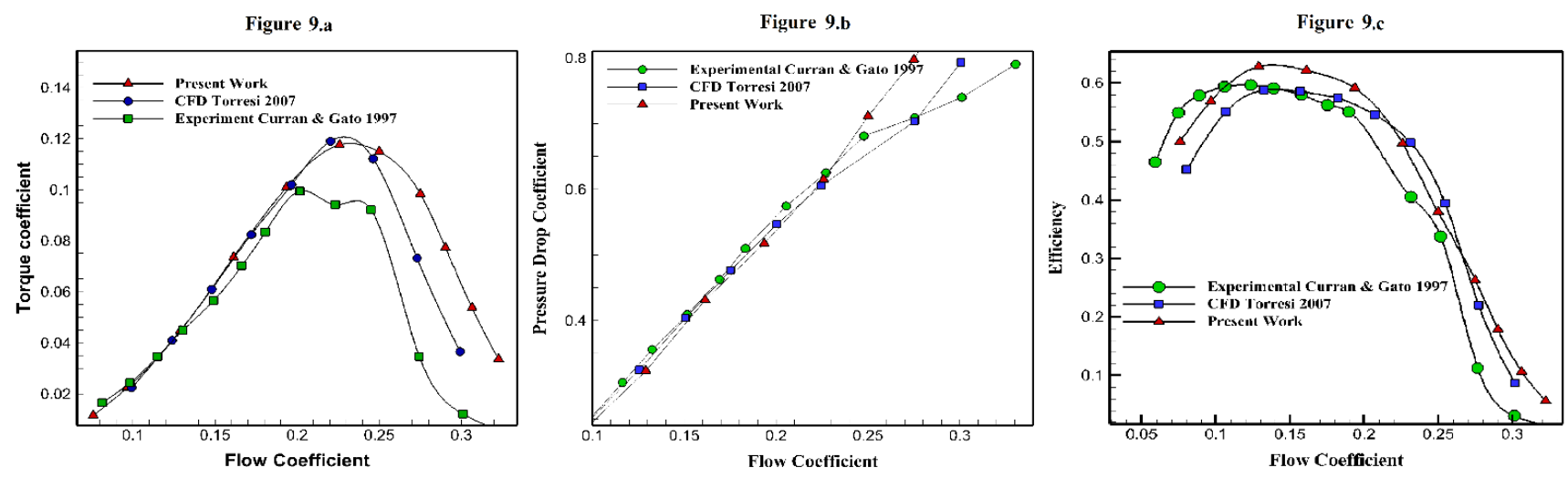

Fig. 9: Performance variables of the present work along with benchmarks data.

\section{Results}

\subsection{The Torque coefficient}

Fig. 10 a shows that the CTB20IFS has a larger stall margin which enables the turbine to generate more power to a wider operational range. The drop in the torque values of CTB20NACA occurs in the flow coefficient of 0.24, while for CTB20IFS torque values continued to rise up-to the flow coefficient of nearly 0.3. In this point, the torque coefficient of the CTB20IFS is nearly $90 \%$ more than that of the CTB20NACA. The maximum torque coefficient and the operational zone of the rotor with IFS profile have been increased by is nearly $38 \%$ and $25 \%$ by order. Fig. $10 \mathrm{~b}$ indicates that the CTB25IFS shows a slight increase in the torque generation in comparison with the CTB25NACA and both designs have similar torque coefficient maxima. In Fig. 10c, the torque coefficient of BSB20IFS reached a significantly higher value than that of the BSB20NACA and the range of torque generation has been widened by $31 \%$. Fig. 10d provides the torque coefficient data of FSB20 rotor. The FSB20NACA rotor does not exhibit a stall point. This is due to the flaw occurred in the RANS turbulence modelling as discussed for highly turbulent stall region in this blade. However, for the before stall points the torque production of IFS profile is more than NACA 
and because of the less turbulent flow at its suction surface the model captures the stall onset and the increasing trend stops at a flow coefficient of 0.3. Fig. 10 e displays the torque coefficient of VTB20 rotor. The maximum torque coefficient of VTB20IFS profile occurs at a flow coefficient of 0.32 , which is $21 \%$ higher than the flow coefficient at the maximum torque coefficient of VTB20NACA. The amount of this maximum for VTB20IFS is 71\% greater than for VTB20NACA. Finally, fig. $10 \mathrm{f}$ shows the torque values of VTB25 blade. As seen the IFS profile exhibits $47 \%$ larger maximum torque and an $11 \%$ increase in the operational range compared with the NACA profile.
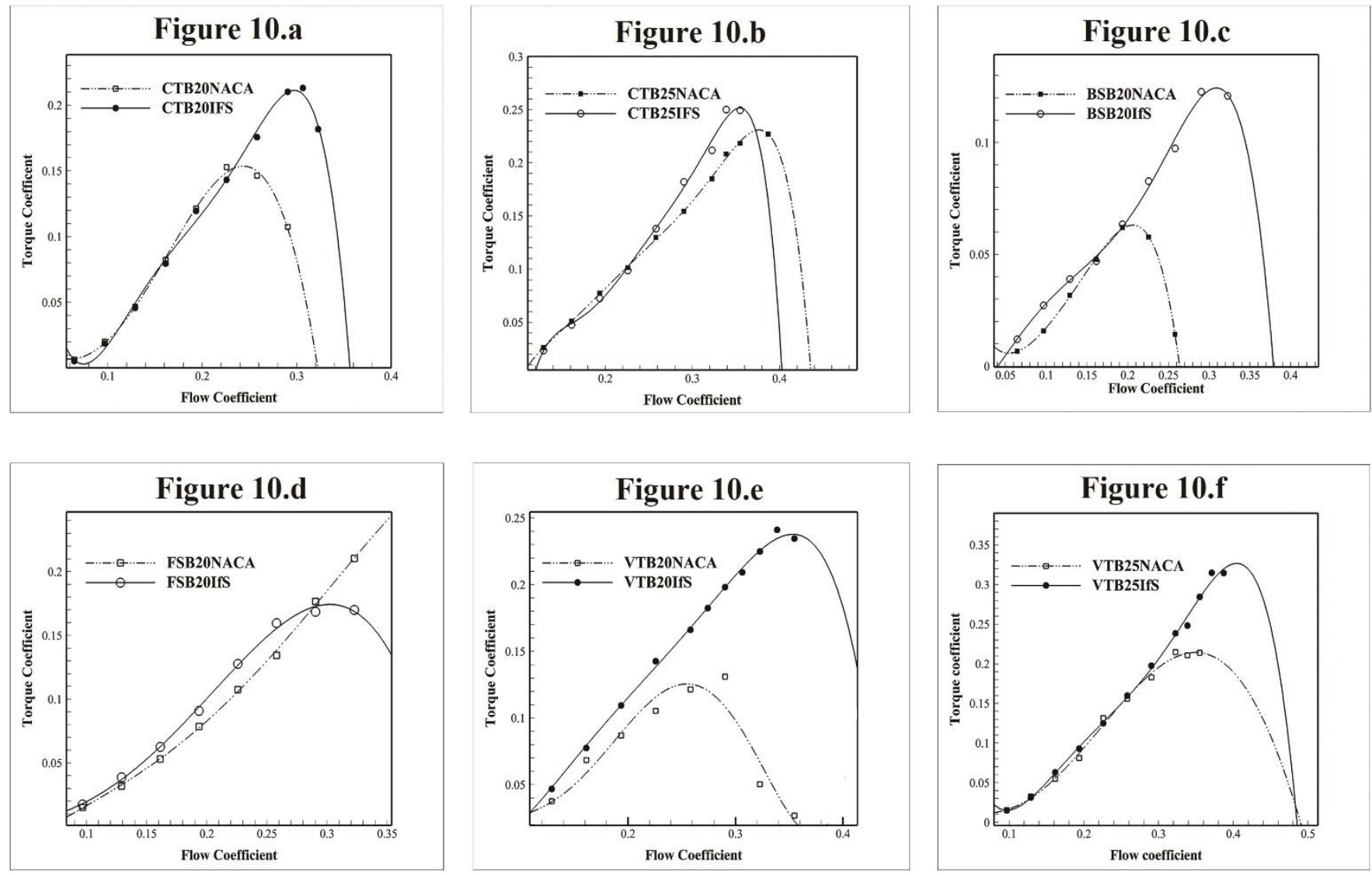

Fig. 10. The torque coefficient diagram for different simulated blades with the NACA and IFS profiles as their sectional profile. 


\subsection{Pressure drop coefficient curves}

Figure 11 demonstrates almost linear proportion between the pressure drop coefficient and the flow coefficient. This is expected for Wells turbines, based on previous studies and is ideal for an OWC system $[1-4,16]$. However, the gradient of the line between the pressure drop coefficient and the flow coefficient undergoes a disorder due to stalling. In some cases, a nonlinearity occured in the flow above the flow coefficient at which stalling occurred. Figure 11 shows that the loss of the static pressure in the rotors with IFS profile is nearly $20 \%$ larger than NACA with the CTB20IFS and VTB20IFS experience the lowest increase in the pressure loss among other blades. Correspondingly, they produced the largest torque values that offset the greater pressure loss in comparison with NACA. Therefore, their efficiency would not be affected significantly.

The IFS profile generates more pressure drop than the NACA profile (Fig. 11a, 11b). While this can reduce the maximum efficiency of the turbine, it could be considered advantageous, as OWCs devices where the pressure difference between the inlet and the outlet is great, a turbine capable of operating under large pressure differences is needed. In real applications, the increase in pressure difference results in higher flow velocities passing the critical flow coefficient of conventional profiles such as NACA. To avoid this condition, several solutions have been proposed and tested [9, 16, 22]. One solution is utilization of several turbines sequentially in one site. However, this increases the design cost and complexity. Another solution is a pressure relief valve control system to release the excessive air pressure, which also has drawbacks $[9,22]$. Another solution is to increase the rotational velocity of the blade to adjust the flow coefficient in the higher flow velocities formed by the large pressure differences. This method is not recommended since high angular velocity along with the high-pressure difference might create cause the tips of the blades to exceed the speed of sound and create Mach waves. This will result in additional loss due to drag waves to the power-generating capacity of the system [20,22]. The IFS profile is able to produce a suitable efficiency even under the larger pressure differences which means that no preventative actions are necessary. One of the powerful and intrinsic factors in the production of a pressure drop in a profile is the blunt trailing edge. Such an edge is inherent in the geometry of the IFS profile. However, the blunt trailing edge is advantageous in a cascade with a stagger angle of 90 , which is the case for the Wells turbine blade, as it influences the formation and development of the boundary layer downstream of the blade that postpones the stall. Moreover, a blunt tail can decrease structural damage and maintenance costs [16].

Figure 11.a

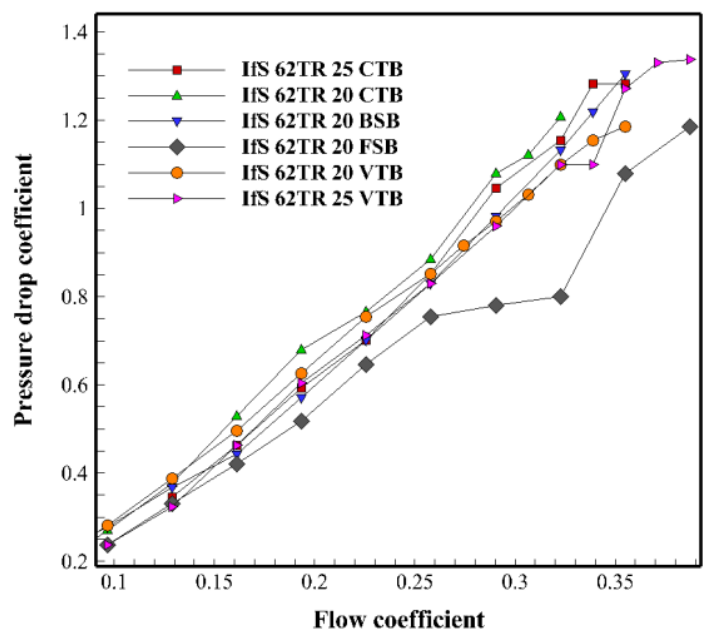

Figure 11.b

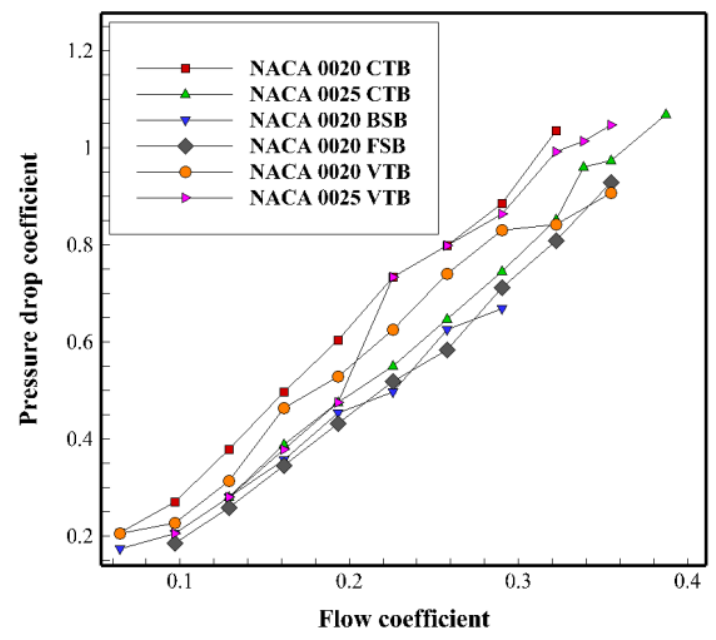

Fig. 11. Pressure drop coefficients of the six different designs with NACA and IFS profiles drawn altogether.

\subsection{Efficiency curves}

Fig. 12a shows the CTB20IFS has the highest maximum efficiency among the other blades but the efficient range of this blade was not increased substantially to meet our goal. In the second place, 
VTB20IFS with maximum efficiency of slightly larger (1\%) can work adequately efficient up to a much larger point. In the OWC sites larger range is more advantageous than higher maximum efficiency [8]. We can see in Fig. 12 e that this blade remains operational in the flow coefficients located after the stall point of its corresponding NACA profile. In the BSB20 case as shown in Fig. 12c, the IFS geometry has a significantly lower peak efficiency than the NACA geometry. For the FSB20 blade in fig. 12d we can see, the IFS profile also has a lower peak efficiency than the NACA profile. In fig. 12e, for VTB20IFS blade, the maximum efficiency is approximately $6 \%$ greater than the equivalent NACA blade and the efficiency range is enlarged by $24 \%$ more than any other blade with the IFS profile. For example, for a flow coefficient of 0.36, the 2VTB20NACA is nearly zero efficient, while the VTB20IFS has an efficiency of $34 \%$. Finally, results indicate that VTB20IFS is significantly effective in addressing the problem of narrow operational range and sudden stall of the Wells turbine, which was the primary goal stated in the introduction section. For CTB25, VTB25, BSB20 and FSB20 as shown in Figs. 12 b, 12f, 12c and 12d the IFS profile is predicted to have a peak efficiency that is significantly lower than the NACA equivalent. This is due to the excessive increase in the static pressure loss over the blades. They have comparatively weaker performance than the same blades with the NACA profiles. Therefore, the only IFS case that satisfies the performance gaps of the Wells turbine to a great extent is VTB20. High torque generation and smaller losses enabled the VTB20IFS turbine to have a considerable increase in the operating range with good efficiency.
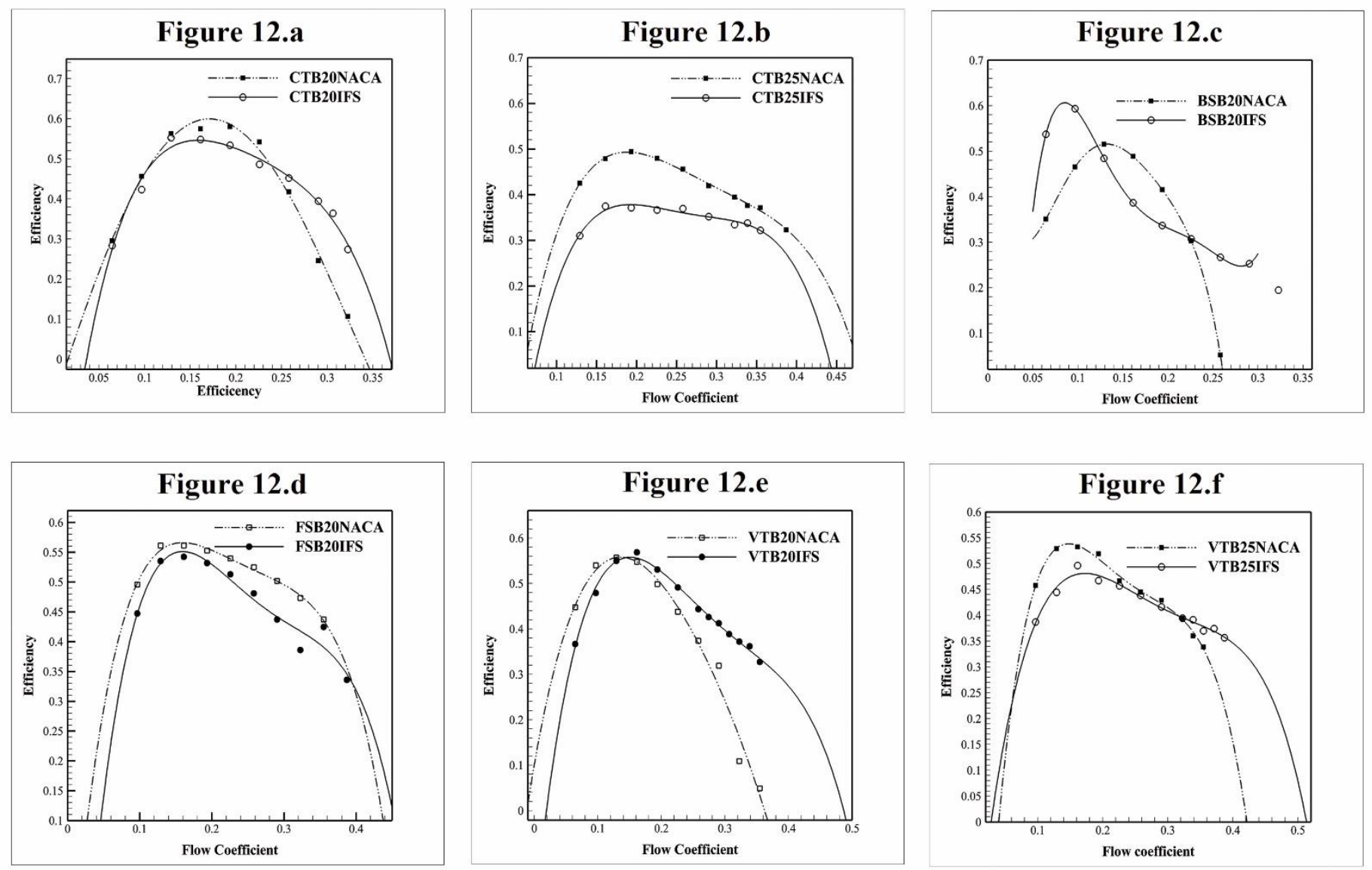

Fig. 12. Predicted efficiencies of the different blade geometries.

To conclude, Table 5 summarizes the key results of the above data for different blades tested with IFS profile.

Table 5. Main performance variables of the blades with IFS sectional profile. 


\begin{tabular}{|c|l|c|c|c|}
\hline Blade type & $\mathrm{t}$ & $\mathrm{MTC}^{1}$ & $\mathrm{ME}^{2} \%$ & $\mathrm{R}^{2} \%^{3}$ \\
\hline CTB & 0.2 & 0.22 & 55 & 0.24 \\
\hline CTB & 0.25 & 0.24 & 36 & 0.2 \\
\hline VTB & 0.2 & 0.24 & 56 & 0.38 \\
\hline VTB & 0.25 & 0.31 & 33 & 0.33 \\
\hline BSB & 0.2 & 0.13 & 55 & 0.14 \\
\hline FSB & 0.2 & 0.17 & 56 & 0.34 \\
\hline
\end{tabular}

62

63

64

65

66

67

68

69

70

71

72

73

74

75

76

77

78

79

80

81

82

\subsection{Contours}

It is better to choose a flow coefficient in which the flow separation and stall related phenomena is triggered to better compare the behavior of the onset of stall and the vortices formed in the suction side of the two IFS and NACA profiles together. It is clear that for the best case which is the VTB20, flow coefficient of 0.32 is a good selection since it is far enough from the conditions that will lead to the onset of stalling. Reynolds averaged Navier-Stokes equations may have not accurately predicted the results compared to the experimental values in this point. However, in the present work, the CFD technique was able to detect the stall point and predict the right physical trend which is a sudden increase in the pressure drop and a decrease in torque for the VTB20 blade. A noteworthy point is that the predicted amounts of torque for the stall region is greater than the experimental values based on Fig. 9a. Thus, it appears that the CFD set-up provided an underestimate of the detrimental effects of the stall phenomenon which resulted in an overestimate of the torque. For the VTB20NACA case, the flow coefficient of 0.32 is located after its stall point and for the equivalent IFS, the point is near the working zone. Hence, the torque results for the blade with the NACA profile have been predicted to be greater than the actual values. Even with this overestimate, the inferiority of the NACA profile in all cases is obvious and also the qualitative contours corroborate this. Finally, the predicted torques within both the no-stall and stall regions are much higher for the blades with the IFS profile. To investigate the flow behavior, contours of pressure, circumferential velocity and streamlines of the flow field are plotted to include the trailing edge, leading edge, the hub and tip on both the pressureand suction sides of the blade.

\footnotetext{
1 Maximum Torque Coefficient

2 Maximum efficiency

3 Range in which efficiency is larger than 30\%
} 


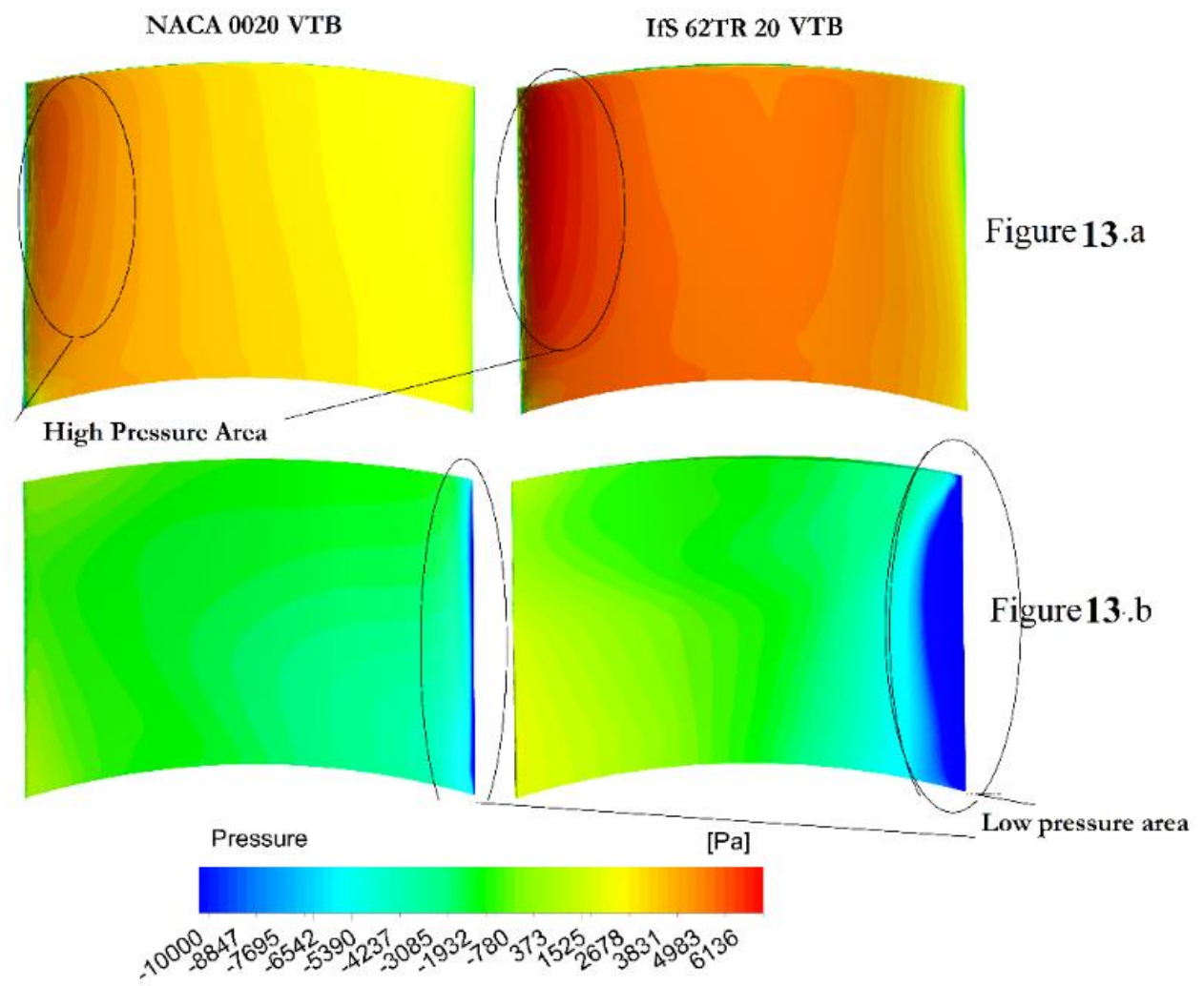

Fig. 13. The pressure distribution contoured on (a) the pressure side and (b) the suction side at a flow coefficient of 0.32 . The leading edge is on the left of each section and the trailing edge is on the right.

Fig. 13 shows the pressure contour on the pressure and suction side of the VTB20IFS. On the pressure side there is a high-pressure zone near the leading edge is more significant than the NACA case. This causes more loading on the surface of the VTB20IFS. On the other side, the low-pressure zone around the leading edge and the tip of this blade is considerably larger than VTB20NACA. These stronger zones increase the fluid velocity on the suction side from the leading edge to the trailing edge on the suction side which will lead to a delay in the formation of a stall. The stronger pressure zones on the pressure side and the suction side of the VTB20IFS makes the flow more likely to pass the lower surface of profile with more momentum and hence less detachment.

In Fig. 14, The circumferential velocity is contoured on the three meridional planes near the leading edge, mid-chord and the trailing edge of the VTB20 blade. Fig. 14a illustrates that the flow field behind VTB20IFS is much stronger than VTB20NACA and tends to remain attached. Based on Fig. $14 \mathrm{~b}$ and $14 \mathrm{c}$, on the tip of the IFS blade, the separation zone formed by the interaction of the lowvelocity region and the tip leakage vortices is smaller than the NACA case. Moving towards the trailing edge region, it can be observed that the separation zone is more bulk, but this zone has a lower intensity and smaller size in the IFS case than in NACA. The momentum and the velocity speeds are substantially greater in the leading edge of the IFS case than in NACA. In the trailing edge, the separated flow is slightly weaker around the hub of the IFS case. This is a critical zone and plays a vital role in the flow behavior of the Wells turbine. The intensity in the tip separation zone is considerably lower for the IFS case. In the vicinity of the leading edge of VTB20IFS, the flow is attached on the suction side while in VTB20NACA the incipient stall occurred in this region and the boundary layer is detached from the suction side. The greater high-velocity field behind the VTB20IFS blade caused the increase in lift and torque generations compared with VTB20NACA. In Fig. 14b, the tip separation behind the NACA profile covered the entire surface of the suction side, 
while in the suction side of VTB20IFS, this zone is comparatively weaker and is confined to the upper quarter of the blade height. Fig. 14c indicates the plane adjacent to the trailing edge region. The separation vortices of the secondary flows reached a fully developed state for the blade with the NACA profile and are intensified in the area close to the hub. This low-velocity zone expands from the tip section towards the hub. However, in the blade with the IFS profile, the developed vortices of the tip region do not reach the lower half of the height of the blade. The flow under the mid-radius and the hub region did not enter into a deep stall condition. Therefore, the lift produced by this blade is much greater.

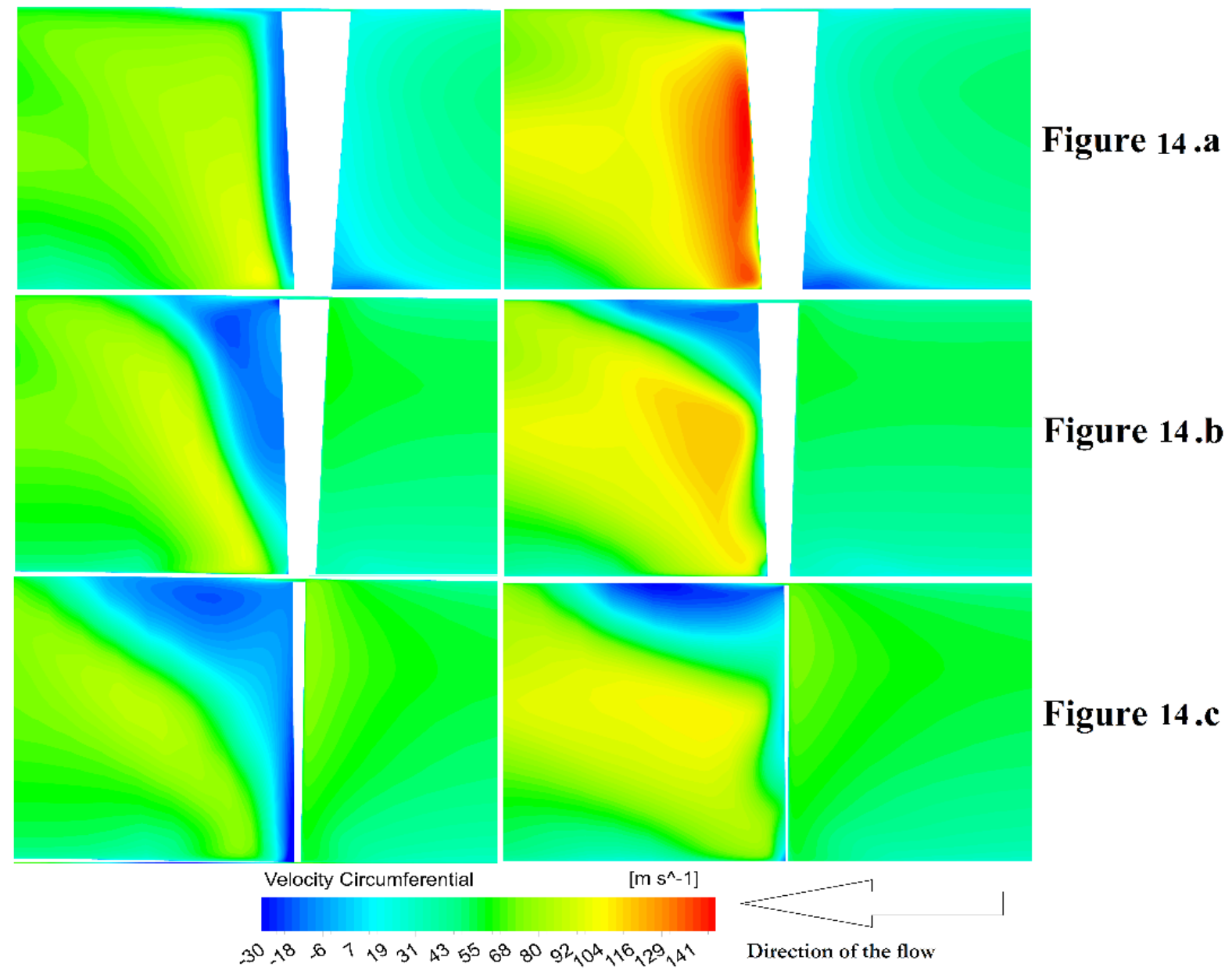

Fig. 14. Circumferential velocity contour on the meridional plane located at (a)10\%, (b) 50\%, and (c) $90 \%$ chord length measured from the leading edge of the VTB20NACA (left) and VTB20IFS

(right).

In fig. 15a, the circumferential velocity is contoured near the hub of the blade with the NACA profile demonstrates a low-velocity region on the suction side. A stall occurs towards the trailing edge after the mid-chord of this profile. In the mid radius plane as shown in Fig. 15b, the blade with the IFS profile has a flow field fully attached to the suction side and therefore generates a greater lift force. The boundary layer fully detaches from the suction side of the blade with the NACA series. However, the flow velocity on the suction side of VTB20IFS remains highly productive up to $30 \%$ chord length. The tip radial plane contours in fig. 15c shows an active low-velocity region produced behind the tip of the NACA profile. Due to the addition of tip leakage vortices effects and the severe stall on its suction side, the tip profile can have no practical lift generation. Therefore, no torque is generated, as observed in the performance diagrams of Fig. 10 and Fig. 12. Though the tip leakage interference influences the tip separation of the blade, the active velocity zone remains at the leading 
edge up to $20 \%$ chord length. Therefore, the stall is less detrimental in the suction side of VTB20IFS blade.
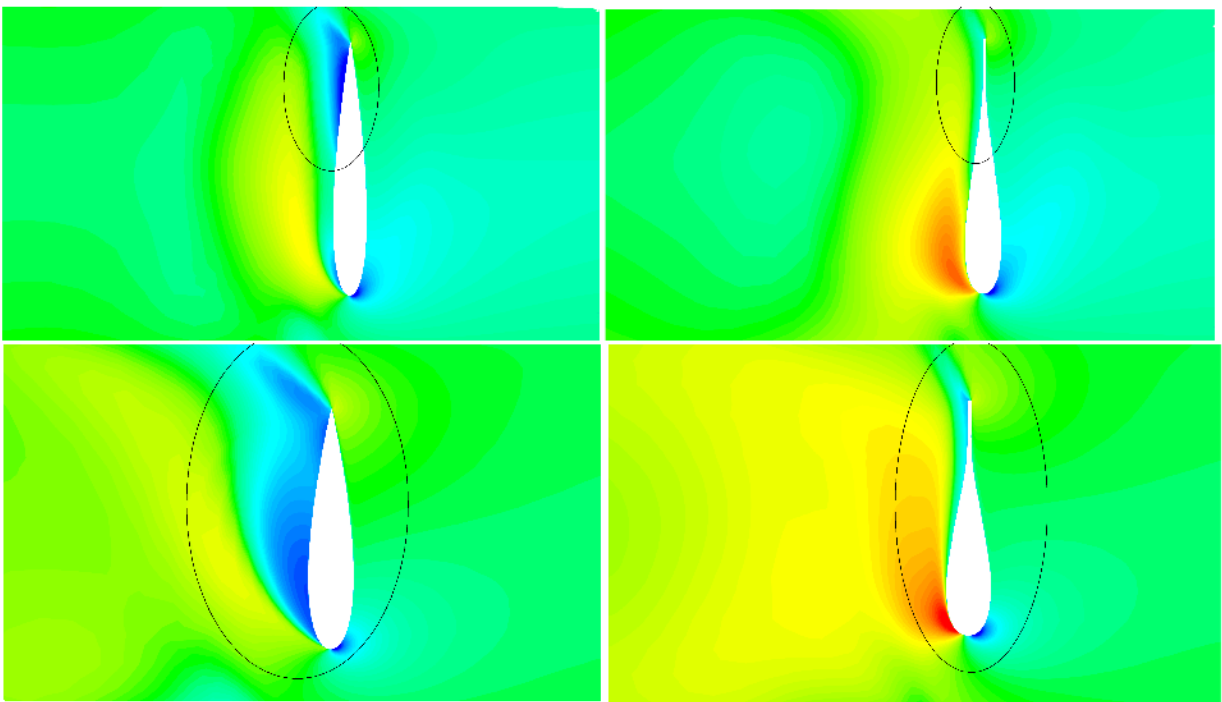

Figure 15.a
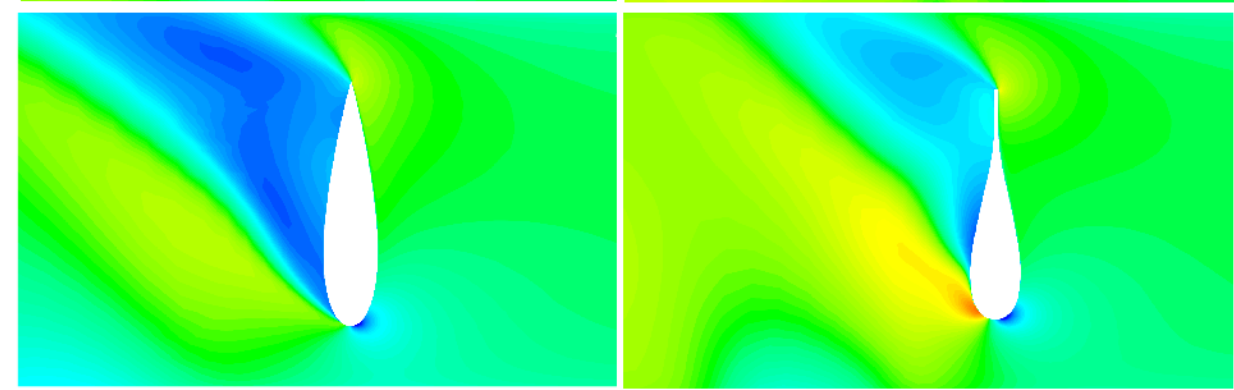

Velocity Circumferential $\left[m s^{\wedge}-1\right]$ $3^{0}, 1^{8} 61,193^{1} 4^{3} 5^{5} 6^{8} 8^{0} 9^{2}, 10^{4}, 16,29,4^{1}$

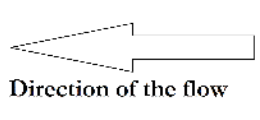

Figure 15 .c

Fig. 15. Circumferential velocity contoured on the radial plane located close to the hub (a) midradius (b) and near tip (c) of the VTB20NACA (left) and VTB20IFS (right).

According to the results, the IFS profile developed the tip leakage vortices into an upward horseshoe vortex which shifted the suction side flow towards the tip zone and injected more momentum into a flow field traveling towards the trailing edge. The occurrence of this phenomenon can be due to the concavity of the profile starting at the mid-chord and vanishing at the trailing edge. The concavity enabled the blade with the IFS profile to have a high-velocity region on the suction side, which postponed the flow separation. The flow under the mid-radius became completely detached in the blades with the NACA profile while it withstood the separation in the blades with the IFS profile.

Fig. 16 a and $16 \mathrm{~b}$ indicate regions on the suction side with separation and secondary flow vortices shed from the blade are comparatively smaller in size and power for VTB20IFS. The separation zone covers approximately $30 \%$ of the suction side area of VTB20IFS whereas for the NACA case this coverage is about $70 \%$ of the suction side area. The three-dimensional sketch of the streamlines agrees with the above results. In contrast with the NACA case, the separation area is confined to the upper quarter height of the VTB20IFS and the flow remained fully attached under this region. As is marked, the lift-producing area in the VTB20IFS is substantially greater than the area in VTB20NACA. 

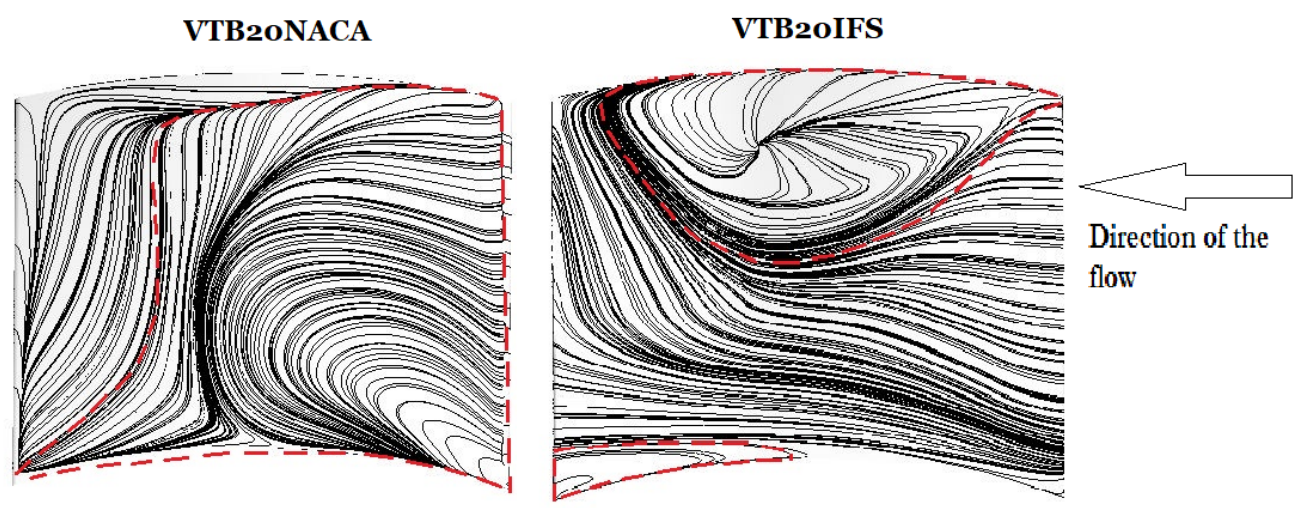

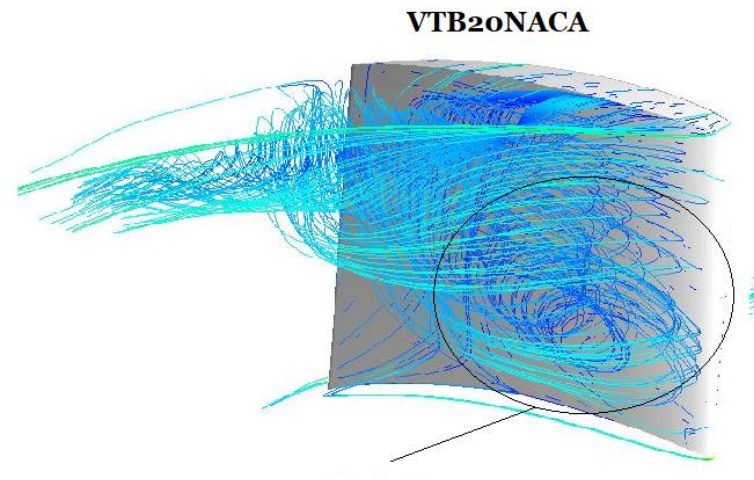

Fully Separated

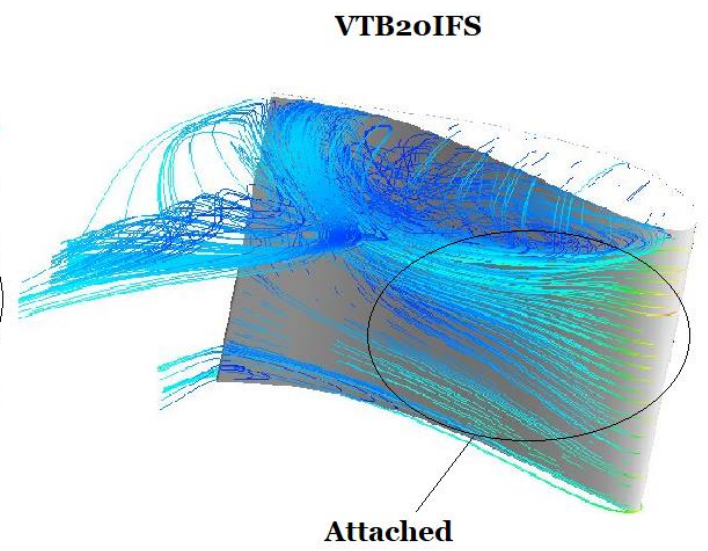

161

162

163

164

165

166

167

168

169

170

171

172

173

174

175

176

177

178

179

Fig. 16a Two-dimensional and Fig. 16b three-dimensional velocity streamlines sketched on the suction side plane of the VTB20 blade geometry.

\section{Conclusions}

In this study, a CFD technique was developed based on the Reynolds averaged Navier-Stokes equations using a structured meshing process. This model was validated in good agreement with the experimental and numerical data of two benchmarks. The IFS profile was tested and compared with the NACA profile for six different blade designs in the application of the Wells turbine. The IFS profile is capable of postponing the separation, compared to the NACA profile. The IFS profile was found to be superior to the NACA geometry in torque generation and, particularly, improving the total performance of VTB20 blade. The obtained results can be summarized as follows:

- The IFS profile was capable of producing much higher torque amounts and generating more power as a result.

- $\quad$ The VTB20IFS profile demonstrated $71 \%$ increase for the maximum torque coefficient and $24.1 \%$ increase for the efficiency range respectively.

- The efficiency results indicated that the VTB20IFS profile is the best shape since it produced the highest efficiency and the widest operational range among others.

- The SS streamline contours demonstrated a smaller separation area for VTB20IFS hence better performance results.

\section{Future Work}

This study aimed to introduce and test a new reference profile for application in the Wells turbine by replacing the NACA profile which has a sudden stall and low torque generation. The IFS profile 
should be tested empirically and used for further studies. In this work, mathematical optimization algorithms for the geometry were avoided due to high numerical costs, but they can be performed on the IFS profile in order to decrease the high-pressure loss of this profile and make it more applicable for usage in Wells turbines. The simultaneous effect of using the IFS profile with flow control strategies can be studied and optimized. The IFS profile is a marine profile used in the water environment. Therefore, a comprehensive study on employing the hydrokinetic type of the Wells turbine with the IFS sectional profile can be done.

Supplementary Materials: The data that support the findings of this study are available from the corresponding author upon reasonable request.

Author Contributions: R. Valizadeh provided all the input, conducted the CFD simulations, carried out the performance analysis and wrote all the parts. R. Valizadeh, M. Abbaspour, M. Saffaripour and C. Hulme-Smith edited the manuscript. All the authors analyzed the results and provided their feedback.

Funding: "This research received no external funding"

Acknowledgments: R. Valizadeh is grateful to: Sharif University of Technology and Computing Center of the Department of Aerospace Engineering. Dr. Madjid Abbaspour, Dr. Mohammad Taeibi-Rahni, Dr. Masoud Boroomand, Mr. Akbari and Mr. Hamed Aslanian.

Conflicts of Interest: The IFS profile used in this study was designed and developed by the Institute of Schiffbau, Hamburg, and the commercial rights of using this profile belongs to their developers. The goal of this work was to provide a scientific analysis and research-based study on this type of profile, and the authors declare no commercial interests on the results of this research.

\section{References}

[1] Amundarain, M., Alberdi, M., Garrido, A. J., Garrido, I., \& Maseda, J. (2010). Wave energy plants: Control strategies for avoiding the stalling behaviour in the Wells turbine. Renewable Energy, 35(12), 2639-2648.

[2] Torresi, M., Camporeale, S., Strippoli, P., \& Pascazio, G. (2008). Accurate numerical simulation of a high solidity Wells turbine. Renewable Energy, 33(4), 735-747.

[3] Energy information administration: international energy annual 2001, Tab. 6.2; 2003. URLhhttp://www.eia.doe.gov/eiai

[4] S. L. Dixon, B. and C. A. Hall. Fluid Mechanics and Thermodynamics of Turbomachinery. Seventh Edition. Elsevier 2014

[5] Lynn, P. A. (2013). Electricity from Wave and Tide. doi:10.1002/9781118701669

[6] Multon, B. (2012). Marine renewable energy handbook. London: ISTE.

[7] Paderi, M., \& Puddu, P. (2013). Experimental investigation in a Wells turbine under bi-directional flow. Renewable Energy, 57, 570-576.

[8] Brito-Melo, A., Gato, L., \& Sarmento, A. (2002). Analysis of Wells turbine design parameters by numerical simulation of the OWC performance. Ocean Engineering, 29(12), 1463-1477.

[9] Shaaban, S. (2016). Aero-economical optimization of Wells turbine rotor geometry. Energy Conversion and Management, 126, 20-31.

[10] Cui, Y., \& Hyun, B. (2016). Numerical study on Wells turbine with penetrating blade tip treatments for wave energy conversion. International Journal of Naval Architecture and Ocean Engineering, 8(5), 456-465.

[11] Soltanmohamadi, R., \& Lakzian, E. (2015). Improved design of Wells turbine for wave energy conversion using entropy generation. Meccanica, 51(8), 1713-1722.

[12] http://news.mit.edu/2008/waves-portugal-tt1217 
[13] Curran, R., \& Gato, L. M. (1997). The energy conversion performance of several types of Wells turbine designs. Proceedings of the Institution of Mechanical Engineers, Part A: Journal of Power and Energy, 211(2), 133-145.

[14] Falcão, A. F., \& Henriques, J. C. (2016). Oscillating-water-column wave energy converters and air turbines: A review. Renewable Energy, 85, 1391-1424.

[15] Shehata, A. S., Xiao, Q., Saqr, K. M., \& Alexander, D. (2016). Wells turbine for wave energy conversion: A review. International Journal of Energy Research, 41(1), 6-38.

[16] Raghunathan, S. (1995). The wells air turbine for wave energy conversion. Progress in Aerospace Sciences, 31(4), 335-386. [17] Torresi, M., Camporeale, S., Strippoli, P., \& Pascazio, G. (2008). Accurate numerical simulation of a high solidity Wells turbine. Renewable Energy, 33(4), 735-747.

[18] Raghunathan, S., \& Tan, C. (1985). Effect of blade profile on the performance of the Wells self-rectifying air turbine. International Journal of Heat and Fluid Flow, 6(1), 17-22.

[19] Raghunathan, S., Tan, C., \& Wells, N. (1982). Theory and performance of a Wells turbine. Journal of Energy, 6(2), 157-160.

[20] Nazeryan, M., \& Lakzian, E. (2018). Detailed entropy generation analysis of a Wells turbine using the variation of the blade thickness. Energy, 143, 385-405.

[21] Kincaid, K. C., \&amp; Macphee, D. W. (2020). Numerical Fluid-Structure Interaction Analysis of a Wells Turbine With Flexible Blades. Journal of Energy Resources Technology, 142(8). doi:10.1115/1.4046385

[22] Raghunatan S., and Beattie W.C. (1996). Aerodynamic performance of contra-rotating Wells turbine for wave energy conversion. Instn Mech Engrs , 210: 431-47

[23] Sharma A., Visbal M., (2017). Numerical Investigation of the Effect of Airprofile Thickness on Onset of Dynamic Stall. Fluid Dynamics, physics.flu-dyn

[24] Setoguchi, T., Kim, T. W., Takao, M., Thakker, A., \& Raghunathan, S. (2004). The effect of rotor geometry on the performance of a Wells turbine for wave energy conversion. International Journal of Ambient Energy, 25(3), 137-150.

[25] Dhanasekaran, T., \& Govardhan, M. (2005). Computational analysis of performance and flow investigation on wells turbine for wave energy conversion. Renewable Energy, 30(14), 2129-2147.

[26] Kim, T., Setoguchi, T., Kaneko, K., \& Raghunathan, S. (2002). Numerical investigation on the effect of blade sweep on the performance of Wells turbine. Renewable Energy, 25(2), 235-248.

[27] M. TAKAO, A. THAKKER, R. ABDULHADI, T. SETOGUCHI. Effect of blade profile on the performance of a large-scale Wells turbine for wave-energy conversion International Journal of Sustainable Energy March 2006; 25: 53-61

[28] Takao, M., Thakker, A., Abdulhadi, R., \& Setoguchi, T. (2006). Effect of blade profile on the performance of a large-scale Wells turbine for wave-energy conversion. International Journal of Sustainable Energy, 25(1), 5361.

[29] Halder, P., Rhee, S. H., \& Samad, A. (2017). Numerical optimization of Wells turbine for wave energy extraction. International Journal of Naval Architecture and Ocean Engineering, 9(1), 11-24.

[30] Halder P., and Samad. A., (2016). Torque and efficiency maximization for a wave energy harvesting turbine: an approach to modify multiple design variables. Int. J. Energy Res

[31] Takao, M., Takasaki, K., Suto, S., \& Setoguchi, T. (2014). 0701 Wells Turbine for Wave Energy Conversion: Effect of 3-dimensional Blade on the Performance. The Proceedings of the Fluids Engineering Conference, 2014. 
267 [32] Mohamed, M., Janiga, G., Pap, E., \& Thévenin, D. (2011). Multi-objective optimization of the airprofile shape

268 of Wells turbine used for wave energy conversion. Energy, 36(1), 438-446.

269 [33] Shaaban, S. (2017). Wells turbine blade profile optimization for better wave energy capture. International 270 Journal of Energy Research, 41(12), 1767-1780.

271 [34] Hashem, I., Hameed, H. A., \& Mohamed, M. (2018). An axial turbine in an innovative oscillating water 272 column (OWC) device for sea-wave energy conversion. Ocean Engineering, 164, 536-562.

273 [35] Gratton, T., Ghisu, T., Parks, G., Cambuli, F., \& Puddu, P. (2018). Optimization of blade profiles for the Wells 274 turbine. Ocean Engineering, 169, 202-214.

275 [36] Molland A.F (2007). Marine Rudders and Control Surfaces, Elsevier

276 [37] Liu, J., \& Hekkenberg, R. (2016). Sixty years of research on ship rudders: Effects of design choices on rudder 277 performance. Ships and Offshore Structures, 12(4), 495-512.

278 [38] Soding, H. (1999). Limits of Potential Theory in Rudder Flow Predictions. Twenty-Second Symposium on 279 Naval Hydrodynamics 1999; 20: 622- 37. [39] H. Thieme, Dipl.-Ing. Design of Ship Rudders. 1962

280 [39] Thieme, H. , 1965 Design of ship rudders. Jarbuch der Schiffbautechnischen Gesellschaft, Vol 56, 1962 or 281 DTMB Translation No. 321

282 [40] El Moctar, (1998), O.A.M., "Numerical determination of rudder forces”, Euromech 374, Poitiers

283 [41] Valizadeh, R., Abbaspour, M., \& Rahni, M. T. (2020). A low cost Hydrokinetic Wells turbine system for 284 oceanic surface waves energy harvesting. Renewable Energy, 156, 610-623. doi:10.1016/j.renene.2020.04.059

285 [42] Shaaban, S., \& Hafiz, A. A. (2012). Effect of duct geometry on Wells turbine performance. Energy Conversion 286 and Management, 61, 51-58.

287 [43] Das, T. K., \& Samad, A. (2020). Influence of stall fences on the performance of Wells turbine. Energy, 194, 288 116864. doi: 10.1016/j.energy.2019.116864

289 [44] Kumar, P. M., Halder, P., Husain, A., \& Samad, A. (2019). Performance enhancement of Wells turbine:

290 Combined radiused edge blade tip, static extended trailing edge, and variable thickness modifications. Ocean 291 Engineering, 185, 47-58. doi: 10.1016/j.oceaneng.2019.05.041

292 [45] Kumar, P. M., \& Samad, A. (2019). Introducing Gurney flap to Wells turbine blade and performance analysis 293 with OpenFOAM. Ocean Engineering, 187, 106212. doi: 10.1016/j.oceaneng.2019.106212

294 [46] Introduction to CFX (2009). Chapter 12," Moving Zones", ANSYS Inc Property

295 [47] ANSYS CFX-Solver Theory Guide (2017). , ANSYS, Inc. Release 18.1. 